\title{
The Education of Deaf and Hard of Hearing People from the Standardization of Foucault
}

\author{
Desueza Delgado A* \\ PhD student in Education, University of Costa Rica, Costa Rica
}

*Corresponding author: Almitra Desueza Delgado, PhD student in Education, University of Costa Rica, Costa Rica, Email: almitra.desueza@ucr.ac.cr; almitradesueza@gmail.com

"We believe, by definition, of course, that the person who has a stigma is not entirely human.

Using this assumption we practice various types of discrimination, where means of which we reduce in practice, although often without thinking, their chances of life. We build a theory of stigma, an ideology to explain his inferiority and account for the danger posed by that person, sometimes rationalizing an animosity that is based on other differences" [1].

\section{Abstract}

The following essay reflections on the processes of educational normality since Foucault's theory. The school is understood as a centre of social regulation in which people are determined by the system for a specific purpose. The case of deaf and hard of hearing people, because of their physical condition they suffer from an exclusionary alterity and anuanced styness within the educational environment, therefore, the reflection proposed is that of the other non-standard, or rather excluded.

Keywords: Deaf Person; Education; Otherhood

\section{As a Preamble}

Being different in a world where everyone is "equal" is a serious problem. The difference will determine, in this case, the position of the person in the world. Some differences make people "super people" other differences make them "infra" people, but in general, all differences challenge that person's "humanity."

This essay will address the difference from the body, from the differentiation of teaching, from the normality of teaching and from the difference itself in the normality of education for deaf people. I will take as a theoretical reference the text of Michael Foucault "The Abnormals", which I will accompany with texts that define the identity of the deaf, the main goal is to think about the normality of education from the abnormality of deafness.

It is necessary to understand the subject from the "normal" body, the one who does not lack or have anything left over, that body that works perfectly and does not need a doctor, a psychiatry, or any other professional who repairs it. It is from that normal body that teaching is normalized, anyone who does not fit within the established parameters is abnormal and requires special education. It is the vision of the doctor, a specialist in normalcy, who determines that deaf people are "abnormal" and therefore need special education. This invites us to think of difference as part of normality in teaching.

\section{The Subject from the "Normal" Body}

"These techniques of standardization and the powers of standardization linked to them are not merely the effect of encounter, harmonization, the connection between themselves of medical knowledge and the judiciary, but in fact, throughout modern society, certain kinds of power - neither medical nor judicial, but another - managed to colonize and suppress medical knowledge and the judiciary; a kind of power that ultimately leads to the court's theatrical 


\section{Philosophy International Journal}

scene, supported, of course, by the judicial institution and the medical institution but which, in itself, has its autonomy and its rules" [2].

The first identity a person receives is based on the physical characteristics that this person possesses, that is the initial contact he has with the world and from there he is classified as an extraordinary person, first class, as a normal person, second class, but as an incomplete person will be a third category, the ashamed class, initiating (for the latter) the cycle of discrimination and prejudice [3] as the person considers himself or herself an "abnormal" person, as his or her physical characteristics (in whole or in part) disarm within the social whole.

An "abnormal" person will always be the victim of the nuance, a constant doubt about his or her humanity, about his condition of being alive, complete; it seems that his or her rights and duties are always being questioned [1]. The absence of a sense, a part of the body, of a capacity, provokes doubt... doubts. His existence is questioned, his life becomes a pathology, surrounded by stereotypes and prejudiced attitudes [4]. The body defines him or her, identifies him or her, confers identity and recognition on him or on her [5].

From this point of view, deaf children become a problem to be solved, in a stigmatized individual, "a person whom strangers can approach at will as long as they are sensitive to situations of this kind" [1]. First, they are medically diagnosed, then they are suggested a treatment, how to return them to normal, through cochlear implants, lip reading, among others; and if that doesn't work they isolate thes thes, they're placed in specialized centers, in special education classes. Their bodies have marked them. Deafness becomes a problem to be treated, there is nothing for them good, they have been marked and they need to get rid of those marks to be normal people, to be able to be a full human being.

From that absence of meaning begins a life of challenges, struggles and problems, or in other words, ends a life of opportunity; their deafness status has stigmatized them, made them abnormal in the eyes of others, their body has generated a pathology and therefore they become the group of excluded, to be socially discriminated against for not belonging to bodily normality.

\section{Teaching from Normality and Abnormality}

Teaching is linked to recognition policies, who can learn, what depends on that person's place in the world, on how he or she is identified and recognized [5]. Typically, the standard determines teaching patterns and the scale of values. Societies decide which discourses individuals will be evaluated with and what power relationships will be established from these discourses [6], with these parameters teaching is established.

It is inscribed in the classroom, what is necessary for the formation of individuals and that is indispensable for their transformation into functional social subjects, in such a way that they establish standards. "The norm, therefore, carries a claim of power. It is not simply, and not even, a principle of intelligibility; it is an element from which a certain exercise of power can be founded and legitimized" [2]. The standards are what will determine teaching and mark the routes of knowledge to which the individual is eligible.

Anything that doesn't fit the norm is abnormal. So if the norm is that classes are taught in Spanish, with a teacher, 20 students and a curriculum, in a building specially created to teach, designed for people who can run and mobilize with their feet, who can use their sight, touch, smell and ear to access the knowledge established by a group of power, in order to serve that group utilitarianly.

A closed coercive curriculum, where there are written and oral evaluations that must be executed at certain times of the school year, with specific tools, which have the function of typecasting and domesticating the thinking of learnings, offer the necessary tools to develop within social functionality, without causing further alterations in the system. Therefore, when subject tapper that does not adapt to the mold, which is not moldable, and that does not correspond to these parameters is abnormal, and therefore has no legitimacy, loses rights or is nullified.

The loss of the legitimacy of teaching by deaf, blind people, among others; causes special rights to be "established". The universal right of children and adolescents to learn is not sufficient, because these people are not subject to their rights, therefore "special" educational and social policies should be created, specific to these people who are not yet social subjects, who need specialized treatment can be shaped, so that they do not get in the way or the social becoming uncomfortable.

Correcting the individual's particularity ensures that any traits that make traffic to normal are eliminated. It is necessary to ensure that the individual will be subjected to the social isolation, that will chain him or her for life, and education is the perfect means to do so, from the beginning he or her, will be shown that he or her has a deficiency, an irregularity, a condition that invalidates him or her socially, for therefore, teaching becomes a special, almost concessional teaching in which deaf people are "forgiven" of being deaf.

Families, as primary socialization organizations are responsible for transmitting with their daily actions the 


\section{Philosophy International Journal}

handicaps of the individual, are responsible for showing them that they will not adapt to their specific linguistic inputs and that they will not learn sign language, because it becomes an abomination that reminds them of the mistake that nature has made against them and isolation will begin within the home.

However, learning and a thirst for knowledge acquisition transcends social prejudices, and the individual will make his or her way into society, trying to acquire a place in the world, even if it seems like a fore gall.

\section{People who are Deaf in the Normality of Teaching}

Deaf people, as victims of normalization, they seek to be accepted, legitimized as they are, with an identity beyond the medical vision [5] as individuals in whom their deafness is part of their cultural identity and social normality [7] without pathological stigmas [4], seek to be valued by themselves, not as a reference for something that must be corrected, because in "the individual's frame of reference to be corrected is much more limited: it is the family itself in the exercise of its internal power or the management of its economy; or, at most, the family in its relationship with the institutions that border or support it. The individual to be corrected will appear in that game, that conflict, that support system between the family and the school, the workshop, the street, the neighborhood, the parish, the church, the police, etc. So that is the field of appearance of the individual to be corrected" [2].

As individuals to correct, they often perceive themselves as a social ballast. Disability incapacitates them, disability disables them, "abnormality" excludes them. They are not disabled per se, because they have some associated "pathology" that excludes them, they are disabled because that was the label they have put on them from the beginning, because they were labeled abnormals, they were stigmatized. However, the deaf community has risen globally, demanding that they be recognized as social subjects as part of normalcy.

In response to the demands of normality of deaf individuals, many families have hoped to perform the cochlear implant until the person has the ability to decide on their own lives; some job and economic opportunities have been provided for deaf people to join economic markets; schools are transforming their exclusion policies into inclusion policies where deaf children and adolescents interact with listeners, where they receive the same classes as listeners, the same content, and their education is normalized.

However, the response to normality, beyond nullating "disability" nullifies individuality and prevents the recognition of various normalities, impedes the ability to build multiple realities that converge in the same legislative corpus, without medical regulations that pathologize individuals and define who are social subjects and who are not social subjects, who deserve to be treated as human beings and who are simply excluded from humanity.

\section{Think of the Difference as Normal in Teaching}

It is necessary to think of the difference as part of the norm, not only "the norm as a rule of conduct and as functional regularity: the rule opposes irregularity and disorder and the norm opposes the pathological and the morbid" [2]. Not just the norm from the disease, the absence of a sense or the lack of a part of the body; if not the norm as a melting pot of possibilities, of interactions of ways of being and of being in the world.

Teaching beyond normality, as regularity typecast in a number of patterns and behaviors, should be thought of as the normality of difference, in which individuals can be socialized and un formed, learn to be part of and belong and not to be typecast and labeled; discover themselves and with them the world around them, they can be determined from who they are and who they want to be, and not about what they own or do not possess.

The normality of teaching from difference allows to create dialogical relationships in diversity, therefore, it would no longer be necessary to form tolerant people, but to educate respectful, responsible and conscious people of the crucible of possibilities of human beings that exist, knowing and knowing in their existence as a part of that whole.

Teaching from difference requires a different thought. A reflection from the recognition of possibilities and not of standardization. It requires an awareness of individuality and difference as a fundamental part of social construction, as part of being subject. It's to stop looking to become.

\section{Final Considerations}

In conclusion, human beings are not only what their body allows them to be, but there is a cluster of possibilities from what they cannot do. The body is not a tool or a conditioner, the body is the human being itself; and just as the color of the eyes changes, so do the possibilities of acts executed or not by the body.

School is an instrument of normalization as an element of power, but this normalization cannot continue to be assumed from a pathological catalogue that makes it impossible to live the fullness of life of each human being from its uniqueness. 
The rule should be the difference, where it is legislate to protect the rights of all and the rights of "others" are not an nulled.

It is necessary to think of school from difference, from education and not from training, from diversity and respect and not from tolerance. A school designed for all from its particularities allows the construction of a society aware of differences and individualities [8-14].

\section{References}

1. Goffman E (1957) Stigma. Identity deteriorated. In: Goffman E (Ed.), Alienation from interaction, Human Relations 10(1): 47-60.

2. Foucault M (2000) The abnormals. Economic Culture Fund.

3. Eckert R (2010) Toward a theory of deaf ethnos: deafnicity -- D/deaf (Homaemon - Homoglosson Homothreskon). J Deaf Stud Deaf Educ 15(4): 317-333.

4. Munoz Baell I, Ruiz M (2000) Empowering the deaf. Let the deaf be deaf. Journal of epistemology and community health 54(1): 40-44.

5. Ohna S (2003) Education of deaf children and the politics of recognition. Journal of deaf studies and deaf education 8(1): 5-10.

6. Foucault M (1999) The order of speech. Fabula TusQuests Editores.

7. Tucker B (1997) The ADA and deaf culture: constrasting precepts, conflicting results. The annals of the american academy of political and social science 549(1): 24-36.

8. Bertagna G (2015) Teachers of tomorrow: premises for a teacher training. Revista española de pedagogía 73(261): 245-262.

9. Foucault M (1976) Watch and punish. Birth of prison. Buenos Aires: I follow XXI editors.

10. Foucault M (1985) A dialogue about power. Altaya.

11. Goffman E (2001) Interns. Essays on the social situation of the mentally ill. Amorrortu.

12. Horkheimer M, Adorno $T$ (1944) Dialectic of enlightenment. South American Publishing House.

13. Witto Mattig S (2012) Michel Foucault, The Abnormals, Ed. Economic Culture Fund, Buenos Aires. pp: 352.

14. Yourniss J (1964) Concept transfer as a function of shifts, age and deafness. Child development 35: 695-700. 